\title{
ACESSIBILIDADE EM PLAYGROUNDS DE ESCOLAS DE ENSINO INFANTIL: UM ESTUDO PAUTADO EM CONCEITOS DE AVALIAÇÃO PÓS-OCUPAÇÃO
}

\author{
BORMIO, Mariana Falcão (1) \\ MAGAGNIN, Renata Cardoso (2) \\ (1) UNESP - Programa de Pós-graduação em Arquitetura e Urbanismo, Doutora \\ e-mail:marianabormio@uol.com.br \\ (2) UNESP - Programa de Pós-graduação em Arquitetura e Urbanismo, Doutora \\ e-mail:magagnin@faac.unesp.br
}

\begin{abstract}
RESUMO
A criatividade da criança a permite se apropriar de todos os espaços para brincar, sendo os playgrounds os preferidos. Considerando a importância destes no desenvolvimento infantil, em especial no processo de ensino - aprendizagem no ambiente escolar, foi definido o objetivo da pesquisa, cujas primeiras etapas são relatadas neste trabalho, que é desenvolver uma Avaliação PósOcupação de playgrounds de escolas de ensino infantil, de maneira a caracterizar como estão sendo projetados, implantados e utilizados, enquanto aspectos de acessibilidade motora. Como metodologia foram adotados abordagens conceitos de Checklist para avaliação da acessibilidade espacial, Análise do deslocamento linear e utilização dos espaços, Walkthrough e Mapa comportamental.

Palavras chave: playground, ensino infantil; Avaliação Pós-ocupação e ambiente construído.
\end{abstract}

\begin{abstract}
The creativity of the child allows you to take ownership of all the spaces to play, being the favourite playgrounds. Considering the importance of these in child development, in particular in the process of teaching-learning in the school environment, has been set the goal of research, whose early stages are reported in this paper, which is to develop an evaluation Post occupation of playgrounds of infant schools, in order to characterize as being designed, deployed and used, while accessibility aspects. As approaches were adopted methodology concepts of spatial accessibility evaluation Checklist, analysis of linear displacement and use of spaces, Walkthrough and Map.
\end{abstract}

Keywords: playground, child education; Post occupancy evaluation and built environment.

\section{INTRODUÇÃO}

A criança inicia seu processo de aprendizado escolar no ensino infantil, que é oferecido de maneira integral de zero aos cinco anos de idade, período este onde o brincar é fundamental para sua formação.

Assim como todo ambiente o escolar e a maneira como ele se apresenta configurado é responsável por exercer influências sobre seu usuário, neste caso 0 aluno, 


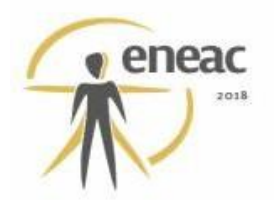

que poderá ser um facilitador tornando o processo de aprendizado prazeroso e seguro ou gerar barreiras dificultando-o.

Ao enfocar a escola direcionada ao ensino infantil cabe destacar que esta é marcada pela presença de espaços lúdicos, visto que crianças nessa faixa etária, necessitam ser estimuladas no seu desenvolvimento de habilidade, capacidades e potencialidades, além de contribuir para a aquisição da cultura e promover a integração entre os seus aspectos físicos, emocionais, afetivos, cognitivos e sociais.

Para Eva Furnari lúdico é tudo aquilo que nos fornece a possibilidade de criatividade, imaginação, fantasia e nos desprende do espaço e do tempo. Moreira e Schwartz (2009) citam que desde a antiguidade teóricos da educação ressaltam a importância do lúdico como recurso para a expressividade e fator para a aprendizagem.

Pode-se dizer ainda que entre os espaços de uma escola de ensino infantil os playgrounds são os que possuem maior expressividade no que diz respeito ao lúdico, mas que muitas vezes ao serem implantados deixam de lado outros importantes aspectos que devem ser enfocados, como por exemplo, a segurança e o acesso para uso de todos os alunos, ou seja, permitem o seu uso autônomo mesmo para aqueles alunos com deficiência.

Considerando 0 contexto exposto define-se como objetivo desta pesquisa 0 desenvolvimento de uma Avaliação Pós-Ocupação dos playgrounds de escolas de ensino infantil, de maneira a caracterizar como esses espaços estão sendo projetados, implantados e utilizados, enquanto aspectos de acessibilidade motora.

Esta pesquisa será desenvolvida através de raciocínio indutivo, com dados colhidos a partir da aplicação de protocolos, com o intuito de explorar a problemática apresentada envolvendo usuários diretos dos local de estudo - playgrounds de escolas de ensino infantil.

Neste trabalho apresenta-se especificamente a contextualização do tema na sociedade contemporânea, enquanto revisão bibliográfica.

\section{EDUCAÇÃO INFANTIL X INCLUSÃO}

"A educação abrange os processos formativos que se desenvolvem na vida familiar, na convivência humana, no trabalho, nas instituições de ensino e pesquisa, nos movimentos sociais e organizações da sociedade civil e nas manifestações culturais (Art $1^{\circ}$ da Lei de Diretrizes e Bases da Educação Nacional, 1996).

A educação para todos é um dever do estado e visa o "pleno desenvolvimento da pessoa, seu preparo para o exercício da cidadania e sua qualificação para o trabalho" (art. 205 da Constituição Brasileira de 1988).

No Brasil, a Lei de Diretrizes e Bases da Educação Nacional (LDB), Lei n 9.394 de janeiro de 1996, disciplina a educação escolar, definindo como seu próprio nome diz suas diretrizes e bases.

De acordo com a LDB a educação básica é obrigatória e gratuita dos quatro aos dezessete anos de idade, iniciando pela pré-escola - ensino infantil (creche - de 0 a 3 anos e préescola de 4 a 5 anos), seguido de ensino fundamental (de 6 a 14 anos) e ensino médio (de 15 a 17 anos). 
Lembra-se que ao definir o direito a educação básica a todos, a LDB não faz distinção entre ser portador de algum tipo de deficiência ou não. E ainda cita a preferencia de inscrição dos alunos com deficiência, transtornos globais do desenvolvimento e altas habilidades ou superdotação, transversal a todos os níveis, graus e modalidades, no sistema regular de ensino.

Ao falar em educação destaca-se a importância do ambiente onde esta é realizada, pois, de acordo com autores como Ribeiro (2004) e Elali (2002) o espaço escolar, com sua distribuição, configuração e usos, têm um importante papel pedagógico ao configura-se como uma fonte de experiências e aprendizagem, que em sua materialidade encontra-se impregnado de signos, símbolos e marcas que comunicam e educam. Ou seja, a maneira como esses elementos se organizam no espaço escolar, exerce impacto sobre o aluno, tanto direto como simbólico, podendo ser um facilitador, como também, um inibidor do comportamento do seu usuário, no processo de ensino-aprendizagem, principalmente para os alunos com deficiências, na medida em que lhes são negadas as condições mínimas de acessibilidade, autonomia e interação.

Loch (2007), também vincula o elemento pedagógico à conformação do espaço, ao citar a existência de uma integração entre o ensino e os indivíduos, destacando que o processo de ensino-aprendizagem não se dá apenas devido ao método pedagógico, mas em todas as dimensões da escola, tanto espaciais como de inter-relação com o meio.

No que tange os aspectos de inclusão frente à educação, Benvegnú (2009) cita como sendo um movimento mundial, de cunho político, cultural, social e pedagógico, que resulta da busca pela defesa do direito de todos os alunos de estarem juntos, aprendendo e participando, sem nenhum tipo de discriminação.

Para Mantoan (2008) a educação inclusiva é um processo que objetiva ampliar a participação das pessoas no ambiente escolar, considerando suas diversidades e particularidades, mas que, para tanto, é necessário desenvolver a reestruturação do sistema de ensino, assim como das práticas vivenciadas nas escolas e consequentemente, a adequação do seu espaço físico, de maneira que esse atenda às diferentes capacidades funcionais da pessoa, com suas singularidades e peculiaridades, no desenvolvimento das atividades.

O autor cita também, que para uma escola ser considerada inclusiva, ela não deve fazer distinção entre seus usuários, ou seja, não os selecionando ou diferenciando com base em julgamento de valores como perfeito e não perfeito, normais e anormais. Portanto, conforme expõem Karagiannis (2000), para que a educação ocorra pautada na diversidade, deve proporcionar a constante interação entre as crianças, pois entende-se que ao criar a oportunidade diária de aprendizado de umas com as outras, direciona-se à atitudes positivas, mutuamente desenvolvidas, de ganhos nas habilidades acadêmicas e sociais e de preparação para a vida em comunidades.

"As escolas inclusivas propõem um modo de organização do sistema educacional que considera as necessidades de todos os alunos e que é estruturada em função dessas necessidades" (MANTOAN, 2003, p.24).

Pode-se considerar também, segundo Loch (2007), que a inclusão em sua procura pelo desenvolvimento da educação dos alunos com deficiência e sua entrada na escola regular, acaba incentivando a busca em tornar as escolas realmente capazes, tanto em termos da qualidade do ensino, como na socialização e na construção de valores positivos nos indivíduos, fazendo da escola um lugar amigável e atrativo.

Entretanto, lembra-se que apesar de toda a expressão que os debates relativos às necessidades de inclusão nos sistemas de ensino têm adquirido nos últimos anos, ainda é evidente as dificuldades enfrentadas pelas pessoas com deficiência, no desenvolvimento 


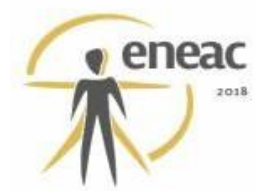

normal de seus estudos, pois se deparam, por exemplo, com práticas discriminatórias, seja enquanto reação dos demais usuários ou pelo próprio ambiente.

\section{O AMBIENTE ESCOLAR X PLAYGROUND}

Como já citado, o ambiente onde o ensino é desenvolvido exerce influencia direta no processo de ensino-aprendizagem, e tratando-se de educação infantil destaca-se dois aspectos, o brincar e o lúdico.

No ano de 2010, o Ministério da Educação em conjunto com a Secretaria de Educação Básica apresentaram as diretrizes curriculares nacionais para essa fase da educação, e entre os objetivos das propostas apresentadas, está a garantia de acesso da criança à brincadeira, considerando para tanto as práticas pedagógicas como eixo norteador de interação, ao entender que dessa maneira, torna-se possível a criação de situações de aprendizagem mediadas para a elaboração da autonomia das crianças nas ações de cuidado pessoal, auto-organização, saúde e bem-estar (BRASIL, 2010).

É importante destacar também a relação que o lúdico apresenta com a educação infantil, que de acordo com Dallabona e Mendes (s/d) autores como Vygotsky (1984), Negrine (1994), Santos (1999), Sneyders (1996), Huizinga (1990), Marcelino (1990), entre outros, é responsável por permitir um desenvolvimento global e uma visão de mundo mais real, pois entendem que é por meio das descobertas e da criatividade, que a criança pode se expressar, analisar, criticar e transformar a realidade.

As autoras citam ainda, que se bem aplicada e compreendida, a educação lúdica poderá contribuir para a melhoria do ensino, que na qualificação ou formação crítica do educando, quer para redefinir valores ou para melhorar o relacionamento das pessoas na sociedade.

Ao analisar o espaço das escolas da educação infantil, identifica-se alguns destinados ao lúdico, sendo os parques infantis o principal tipo de espaço lúdico, e ocupam um importante papel no processo de construção e desenvolvimento de habilidades, capacidades e potencialidades dos alunos, assim como na promoção da integração entre os seus aspectos físicos, emocionais, afetivos, cognitivos e sociais.

Basicamente a composição dos parques infantis é feita por brinquedos, que são responsáveis por dar suporte aos seus usuários, crianças, no ato de brincar, e que para tanto, devem ser pensados de maneira a possibilitar oportunidades específicas para a socialização e aprendizado, além da satisfação das necessidades particulares (VIGOTSKI, 1998; BRASIL, 1998; UNITED STATES ACCESS BOARD, 2005). Brasil (2006b, 2006c,

2006d) complementa ainda citando que esses espaços tendem a ser dinâmicos, brincáveis, exploráveis, acessíveis e a desafiar a curiosidade, a imaginação e a aprendizagem de cada criança.

Mesmo diante de toda a importância atribuída aos playgrounds infantis, observa-se na contramão a maneira como esses estão sendo pensados e implantados, foco de estudo desta proposta de pesquisa, pois na grande maioria dos casos identifica-se a simples demarcação deste local, sem um devido planejamento de sua estrutura. Contexto esse que se agrava quando se fala em usuários com deficiências.

\section{NORMAS PARA PLAYGROUND}

A abordagem do playground pode ser feita por diferentes enfoques. No que diz respeito às normas para sua construção verifica-se que até 0 ano de 2012 a Associação 


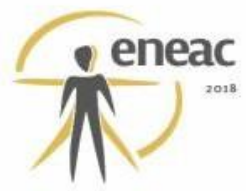

Brasileira de Normas Técnicas (ABNT) considerava como referência a Norma Brasileira (NBR) 14350-1/1999 - Segurança de brinquedos de playground, Parte 1: Requisitos e métodos de ensaio e Parte 2: Diretrizes para elaboração de contrato para aquisição/fornecimento de equipamento de playground, que foram canceladas e substituídas, pela NBR 16071/2012 - Playgrounds, que é composta por sete partes: Parte 1 Terminologia; Parte 2 - Requisitos de segurança; Parte 3 - Requisitos de segurança para pisos absorventes de impacto; Parte 4 - Métodos de ensaio; Parte 5 - Projeto da área de lazer; Parte 6 - Instalação; e Parte 7 - Inspeção, manutenção e utilização.

Pode-se concluir que apesar de ser um começo enquanto preocupações, esta NBR não atender as reais necessidades desse ambiente, pois há uma demanda latente por enfoques complementares como o caráter de acessibilidade.

Em âmbito internacional, Muller et al. (2014) citam duas associações que desenvolveram guias instrucionais com recomendações para tornar playgrounds inclusivos e acessíveis, a ADA - Americanos com Deficiência (American With Disabilities Act) e a AQLPH Associação Québec para entretenimento de pessoas inválidas (Association québécoise de loisir pour personnes Handicapées), cujo objetivo foi orientar projetistas, designers, arquitetos ou outro profissional a desenvolver áreas de lazer acessíveis ou alterar áreas existentes (construídas).

\section{ERGODESIGN - DESIGN INCLUSIVO E ACESSIVEL}

lida (2005) define ergonomia, por uma visão simplificada, como sendo a área de estudo que visa maneiras de se melhor obter a adaptação do trabalho ao homem, não se restringindo somente à sua relação com máquinas e equipamentos utilizados, mas também a toda situação em que ocorre o relacionamento entre o homem no desenvolvimento de atividades, no sistema que esse atua.

Para Moraes e Mont'Alvão (2010), o trabalho compreende qualquer atividade humana realizada com um propósito, particularmente se essa envolver algum grau de experiência ou esforço.

De acordo com Ferreira (2011), a ergonomia possui uma abordagem científica antropocêntrica que se fundamenta em conhecimentos interdisciplinares das ciências humanas e da saúde para, de um lado, compatibilizar os produtos e as tecnologias com as características e necessidades dos usuários e, de outro, humanizar o contexto sociotécnico de trabalho, adaptando-o tanto aos objetivos do sujeito e do grupo, quanto às exigências das tarefas.

A geração de dados das análises ergonômicas pode ocorrer de maneira objetiva, por meio de medições técnicas, ou subjetiva, por exemplo, ouvindo-se as opiniões dos usuários; sempre objetivando a geração de parâmetros que, ao serem implantados, sejam capazes de suprir as necessidades e características físicas, psíquicas e cognitivas do ser humano, de modo a proporcionar um máximo de conforto, segurança e desempenho eficiente, diminuindo, assim, constrangimentos, estresse, fadiga e possíveis acidentes.

lida (2006) cita que o emprego da ergonomia é muito amplo, e que pode ser contemplado na concepção de projetos (Ergonomia de concepção: normas e especificações de projeto), correção (Ergonomia de correção: modificações de situações existentes), organização de layouts (Ergonomia de arranjo físico: melhoria de sequências e fluxos de produção), conscientização (Ergonomia de conscientização: capacitação em ergonomia) e na prevenção (Ergonomia preventiva: evitando erros e melhorando o desempenho); seja de maneira pontual ou macro, envolvendo o ambiente físico, máquinas, mobiliários, 


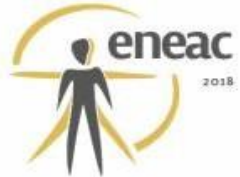

equipamentos, ferramentas, etc., como também os aspectos organizacionais de programação e controle.

Segundo Lucio (2007), através da integração entre acessibilidade, antropometria, design ergonômico, design universal, ergonomia e usabilidade, torna-se possível empregar soluções mais condizentes com as reais necessidades dos usuários, permitindo contemplar diversas potencialidades, que não seriam adequadamente atendidas através da ótica de uma única área do conhecimento.

A abordagem da inclusão de qualquer ser humano está condicionada entre outros fatores à acessibilidade, ou seja, às condições que são propiciadas ao usuário para que este possa utilizar o ambiente, equipamento, etc..

Segundo a ABNT-NBR 9050/2015, acessibilidade pode ser compreendida como sendo a "possibilidade e condição de alcance, percepção e entendimento para utilização, com segurança e autonomia, de espaços, mobiliários, equipamentos urbanos, edificações, transportes, informação e comunicação, inclusive seus sistemas e tecnologias, bem como outros serviços e instalações abertos ao público, de uso público ou privado de uso coletivo, tanto na zona urbana como na rural, por pessoa com deficiência ou mobilidade reduzida" (ABNT, 2015, p. 02).

\section{AVALIAÇÃO PÓS-OCUPAÇÃO}

Avaliação Pós-ocupação (APO), segundo Ornstein, Bruna e Romero (1995), diz respeito a uma série de métodos e técnicas que diagnosticam fatores positivos e negativos do ambiente no decorrer do uso, a partir da análise de fatores socioeconômicos, de infraestrutura e superestruturas urbanas dos sistemas construtivos, conforto ambiental, conservação de energia, fatores estéticos, funcionais, comportamentais, entre outros.

Almeida (2001) complementa tal afirmação ao considerar que a analise de ambientes durante o uso tem se mostrado uma eficiente forma de investigar como as pessoas movimentam-se nele, e que compreender como são construídos os referenciais em relação ao espaço, pode tornar explícito o conhecimento sobre o papel dos elementos arquitetônicos na composição do espaço vivencial.

Ornstein (1996) atribui à APO um contexto interdisciplinar de aplicação que utiliza-se de métodos e técnicas para levantamento e análise de dados, a partir dos quais são diagnosticados aspectos construtivos, funcionais e de conforto, como também econômicos, estéticos e comportamentais de ambientes em uso, considerando diferentes pontos de vistas, os técnicos dos avaliadores e projetistas, e o subjetivo dos usuários e clientes.

A importância desse tipo de abordagem, de acordo com Ornstein (2016), deve-se ao princípio de que edificações e espaços livres postos em uso, qualquer que seja a função, devem estar em permanente avaliação, quer do ponto de vista construtivo e espacial, quer do ponto de vista de seus usuários. Neste contexto, a autora considera que o desenvolvimento da APO tem como objetivo obter subsídios para corrigir, sistematicamente, as falhas e aferir eventuais acertos, bem como, a partir da realimentação do processo projetual, definir diretrizes para novos projetos semelhantes.

E Evans e McCoy (1998) e Ornsteins (2005) corroboram ao citar que ao aplicar ao ambiente em uso, tem-se como resposta o aferimento do desempenho físico deste ambiente e consequentemente um diagnóstico comum de acertos e falhas, que serve de insumos para alimentar programas de manutenção, uso e operação dos próprios estudos de caso e diretrizes para futuros projetos semelhantes. 


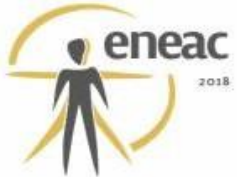

\subsection{Tipos e etapas da APO}

Segundo Rabinowitz (1979, p. 339-404), as APOs poder ser de três tipos: técnica, funcional e comportamental, conforme segue abaixo:

- Avaliação técnica: refere-se aos elementos técnicos, nem sempre percebidos em sua importância, definem o ambiente de fundo para as atividades humanas e tratam da saúde, segurança e bem estar dos usuários. Os fatores técnicos, comumente avaliados são: paredes externas, tetos, segurança contra incêndio, estrutura, acabamento interno, iluminação, sistemas elétricos e hidráulicos, acústica, aquecimento, ventilação e condicionamento do ar;

- Avaliação funcional: são aqueles fatores que apoiam diretamente as atividades humanas e o desempenho organizacional. São basicamente: grupos de localização (agrupamento ou separação de áreas de acordo com o fluxo de trabalho nas edificações); circulação; fatores humanos (medidas antropométricas e ergonomia são consideradas no desenvolvimento de normas e projetos adequando;

Uma APO compreende várias etapas: coleta ou levantamento de dados, diagnóstico, recomendações para o ambiente - estudo de caso e insumos para os novos projetos.

Entre os principais métodos/técnicas atualmente utilizados nessa área, Elali (2002) destaca: vistorias técnicas, levantamentos dos aspectos arquiteturais e mobiliários; medições do dimensionamento e dos fatores físicoambientais como temperatura, luminosidade, ruído; questionários e formulários; checklist, entrevistas; observação de comportamento e usos; documentação através de imagens fotográficas e vídeos; documentação gráfica - projeto arquitetônico, croquis e simulações. E Duarte (2000) complementa considerando que as avaliações técnicas podem ser realizadas utilizando-se métodos de observações - vistorias "in loco" e por meio de medidas dos parâmetros físicos; enquanto que, a opinião dos usuários pode ser coletada através de entrevistas e questionários.

Em relação às ferramentas de avaliação da qualidade habitacional, Coelho (2006) escreve que as ferramentas de APO (as quais podem ser constantemente melhoradas), ligadas à capacidade de análise e observação, constituem-se em uma tendência de trabalho considerada adequada para o atendimento da qualidade arquitetônica e da satisfação residencial. Somando-se à APO, considera-se também a estreita relação entre a qualidade habitacional e a gestão do processo de projeto. Aspectos relevantes em relação à gestão do processo de projeto, seu papel no atendimento, a qualidade dos espaços construídos, notadamente nas habitações.

\section{ESTUDO DE CASO}

Conforme citado anteriormente, este trabalho relata as primeiras etapas de uma pesquisa em desenvolvimento, cujos estudos iniciaram por uma ampla revisão bibliográfica a respeito do tema, que forneceu o embasamento teórico necessário para a estruturação da ferramenta metodológica de avaliação a ser utilizada, que engloba conceitos de Checklist para avaliação da acessibilidade espacial, Análise do deslocamento linear e utilização dos espaços, Walkthrough e Mapa comportamental.

Paralelo à estruturação da ferramenta foi desenvolvido um estudo que quantificou e identificou as escolas de ensino infantil das cidades de Bauru e Agudos, localizadas no interior do estado de São Paulo, Brasil, assim como seus alunos e os tipos de deficiência que possuem. A Tabela 01 apresenta os dados obtidos na cidade de Agudos, sendo a EMEI (Escola Municipal de Ensino infantil) "Anésia B S Bigarelli” definida como local para 
aplicação do protocolo desenvolvido, de maneira a identificar se sua estrutura atende os objetivos da pesquisa, assim como se é de fácil entendimento e aplicação pelo avaliador.

A definição da EMEl foi feita considerando a presença de um maior número de deficiência nos alunos matriculados.

Tabela 1: Mapeamento das EMEls da cidade de Agudos e deficiências de seus alunos

\begin{tabular}{|c|c|c|}
\hline Escola & $\begin{array}{l}\text { Crianças } \\
\text { matriculadas }\end{array}$ & Diagnóstico \\
\hline EMEI “Anésia B S Bigarelli” & $\begin{array}{l}2 \\
2 \\
1 \\
2\end{array}$ & $\begin{array}{l}\text { Síndrome de Down } \\
\text { Transtorno do Espectro Autista } \\
\text { Paralisia Cerebral (cadeirante) } \\
\text { Transtornos Mistos do } \\
\text { Desenvolvimento (F83) }\end{array}$ \\
\hline EMEI "Prof. ${ }^{a}$ Clélia Napoleone Crema" & $\begin{array}{l}1 \\
1\end{array}$ & $\begin{array}{l}\text { Transtorno do Espectro Autista } \\
\text { Transtornos Mistos do } \\
\text { Desenvolvimento (F83) }\end{array}$ \\
\hline “Unidade Infantil Prof. Diomira N Paschoal” & 1 & Transtorno do Espectro Autista \\
\hline EMEI “Vereador José Octaviani Filho” & $\begin{array}{l}1 \\
1\end{array}$ & $\begin{array}{l}\text { Transtorno do Espectro Autista } \\
\text { Transtornos Mistos do } \\
\text { Desenvolvimento (F83) }\end{array}$ \\
\hline Maria de Nazaré Creche Escola & 1 & Síndrome de Down \\
\hline EMEI "Prof. a Thereza Yvoneti Perni” & $\begin{array}{l}1 \\
1 \\
2 \\
2\end{array}$ & $\begin{array}{l}\text { Deficiente Visial (Baixa Visão) } \\
\text { Paralisia Cerebral (cadeirante) } \\
\text { Deficientes Auditivos } \\
\text { Transtornos Mistos do } \\
\text { Desenvolvimento (F83) }\end{array}$ \\
\hline Centro de Educação Infantil Lar da Criança & 2 & $\begin{array}{l}\text { Transtornos Mistos do } \\
\text { Desenvolvimento (F83) }\end{array}$ \\
\hline EMEFEI “Prof. Sérgio Augusto Mainini” & $\begin{array}{l}1 \\
1 \\
1\end{array}$ & $\begin{array}{l}\text { Transtorno do Espectro Autista } \\
\text { Síndrome de Down } \\
\text { Deficiência Visual e Transtornos } \\
\text { Mistos do Desenvolvimento (F83) }\end{array}$ \\
\hline EMEFEI "Prof. a Silvia M Amato Trigo" & $\begin{array}{l}1 \\
1\end{array}$ & $\begin{array}{l}\text { Transtorno do Espectro Autista } \\
\text { Microcefalia }\end{array}$ \\
\hline EMEI “Antonio Travain” & $\begin{array}{l}1 \\
1\end{array}$ & $\begin{array}{l}\text { Transtorno do Espectro Autista } \\
\text { Transtornos Mistos do } \\
\text { Desenvolvimento (F83) }\end{array}$ \\
\hline
\end{tabular}

Fonte: Secretaria da Educação de Agudos, 2017.

As imagens a seguir apresentam o local em estudo.
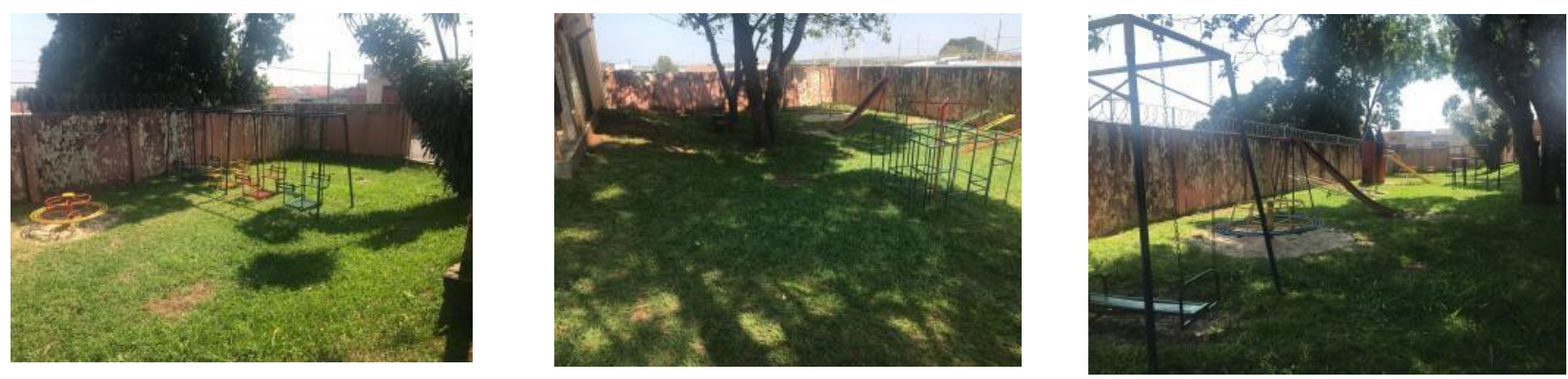

Fonte: Autoras, 2018 


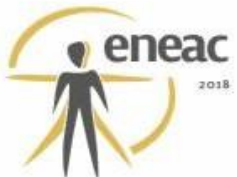

\section{CONSIDERAÇÕES FINAIS}

Conforme apresentado ao longo deste trabalho, e que justifica o desenvolvimento da pesquisa em questão, em contramão a importância que os playgrounds possuem no desenvolvimento da criança, em especial cita-se o processo de ensino-aprendizagem, está a maneira como estes estão sendo pensados e implantados enquanto espaços acessível que propiciam o uso indiscriminado, ou seja, sem apresentar barreiras físicas aos diferentes possíveis tipos de usuários.

Cabe destacar que mesmo antes de ter sido realizado o primeiro pré-teste da ferramenta, foi possível identificar apenas pela visita inloco que o local apresenta problemas na sua estrutura, pois é visível a falta de rampas, caminhos de acesso e equipamentos que tornem os brinquedos acessíveis.

\section{REFERÊNCIAS BIBLIOGRÁFICAS}

ASSOCIAÇÃO BRASILEIRA DE NORMAS TÉCNICAS. NBR 9050: Acessibilidade a edificações, mobiliário, espaços e equipamentos urbanos. $3^{\circ}$ ed. Rio de Janeiro, 2015. 148 p..

ASSOCIAÇÃO BRASILEIRA DE NORMAS TÉCNICAS. NBR 14350: Segurança de brinquedos de playground. Parte 1: Requisitos e Métodos de Ensaio. Rio de Janeiro: ABNT, 1999.

BRASIL. Constituição Federal. Texto constitucional promulgado em 5 de outubro de 1988. Brasília: Senado Federal. 1998.

Decreto Lei 5.296, de 2 de dezembro de 2004. Regulamenta as Leis nos 10.048, de 8 de novembro de 2000, que dá prioridade de atendimento às pessoas que especifica, e 10.098, de 19 de dezembro de 2000, que estabelece normas gerais e critérios básicos para a promoção da acessibilidade das pessoas portadoras de deficiência ou com mobilidade reduzida, e dá outras providências. Brasília: Senado Federal. 2004.

Lei 10.048, de 8 de novembro de 2000. Dá prioridade de atendimento às pessoas que especifica, e dá outras providências. Brasília: Senado Federal. 2000a.

Lei 10.098, de 19 de dezembro de 2000. Estabelece normas gerais e critérios básicos para a promoção da acessibilidade das pessoas portadoras de deficiência ou com mobilidade reduzida, e dá outras providências. Brasília: Senado Federal. 2000b.

Lei Federal 12.796/2013. Altera a Lei no 9.394, de 20 de dezembro de 1996, que estabelece as diretrizes e bases da educação nacional, para dispor sobre a formação dos profissionais da educação e dar outras providências. Ministério da Educação. 2013. 


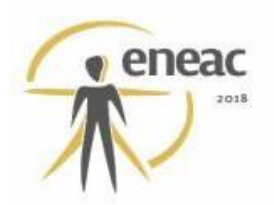

Ministério da Educação e do Desporto. Secretaria de Educação especial. Subsídios para organização e funcionamento de serviços de educação especial: área de deficiência visual. Série Diretrizes 8. Brasília: MEC-SEESP, 1995. 58 p.

Ministério da Educação. Atendimento Educacional Especializado em Deficiência Visual: Deficiência Visual. SÁ, Elizabet Dias de; CAMPOS, Izilda Maria de; SILVA, Myrian Beatriz Campolina. Brasília: Secretaria de Educação Especial. 2007.

Ministério da Educação. Espaços educativos. Ensino fundamental. Subsídios para elaboração de projetos e Adequação de edificações escolares. Elaboração Rogério Vieira Cortez e Mário Braga Silva. Coordenação-geral José Maria de Araújo Souza. FUNDESCOLA/ MEC. Brasília. 2002.

Ministério da Educação. Lei Federal 9.394, de 20 de Dezembro de 1996. Estabelece as diretrizes e bases da educação nacional. 1996.

Ministério da Educação. Programa de Capacitação de Recursos Humanos do Ensino Fundamental: Deficiência Visual. BRUNO, Marilda M. Garcia; MOTA, Maria Glória B. da. Brasília: Secretaria de Educação. 2001.

Ministério da Educação. Secretaria de Educação Básica. Parâmetros básicos de infraestrutura para instituições de educação infantil. Brasília: MEC, SEB, 2006.

Ministério da Educação: Deficiência Visual. Cadernos da TV Escola: GIL, Marta (org.) - Brasília: Secretaria de Educação a Distância. 2000.

Ministério das Cidades. Brasil Acessível. Programa brasileiro de acessibilidade urbana. Cadernos 1, 2, 3, 4, 5 e 6. Secretaria Nacional de Transporte e da Mobilidade Urbana. Brasília. 2007.

CARVALHO, Telma Cristina Pichioli de. Arquitetura escolar inclusiva: construindo espaços para educação infantil. Tese (Doutorado). Programa de Pós-Graduação em Arquitetura e Urbanismo. Universidade de São Paulo. EESC/USP. São Carlos. 2008.

DAISH , John; GRAY, John; Gray; KERNOHAN, David; SALMOND,Anne. Post occupancy evaluation in New Zealand. In: Design Studies

VOLUME 3, ISSUE 2, APRIL 1982, PAGES 77-83. DISPONÍVEL: HTTP://WWW.SCIENCEDIRECT.COM/SCIENCE/ARTICLE/PII/0142694X82900527. ACESSO: 28 DE ABR DE 2017.

DIAS, Edmilson Queiroz. Acessibilidade espacial e inclusão em Escolas Municipais de Educação Infantil. Dissertação (Mestrado) - Universidade Estadual Paulista. Faculdade de Arquitetura, Artes e Comunicação, Bauru, 2016. 206 p..

DISCHINGER, M. et al.. Incluir brincando. Inclusão: Revista da Educação Especial. Brasília, volume 4, número 2, p. 38-45, jul./out. 2008.

DISCHINGER, Marta; BINS ELY; Vera Helena Moro; BORGES, Monna Michelle Faleiros da Cunha. Manual de acessibilidade espacial para escolas: o direito à escola acessível. Brasília: Ministério da Educação, Secretaria de Educação Especial, 2009

DOEHME. V. D. Atividades lúdicas na educação - o Caminho de tijolos amarelos do aprendizado. Texto integrante dos Anais do XVII Encontro Regional de História - O lugar da História. ANPUH/SPUNICAMP, 2004. Disponível em: http://www.anpuhsp.org.br/sp/downloads/CD\%20XVII/ST\%20VIII/Vania\%20DAngelo\%20Do hme.pdf. Acessado 09 de maio de 2017.

EVANS, G. W.; MCCOY, J. M.. When buildings don't work: The role of architecture in human health. In: Journal of Environmental Psychology, 18, 85-94. 1998. 


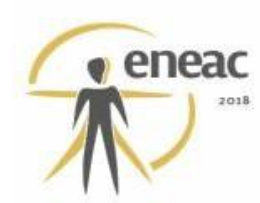

ELALI, G. A.. Ambientes para Educação Infantil: um quebra-cabeça? Contribuição Metodológica na avaliação Pós-ocupação de edificações e na elaboração de diretrizes para projetos arquitetônicos na área. 2 v. 2002. 305 f. Tese (Doutorado em Estruturas Ambientais e Urbanas) - Faculdade de Arquitetura e Urbanismo, Universidade de São Paulo, São Paulo, 2002.

FERRAZ, Vera; FILGUERIAS, Lúcia. A bengala como um instrumento lúdico na orientação e mobilidade do deficiente visual. Disponível em: http://www.deficienciavisual.pt/txt-bengala_instrumento_ludico_OM.htm Acesso em: dezembro/2015.

IIDA, I. Ergonomia: projeto e produção. $2^{\circ}$ Ed. Ver.e ampl. São Paulo: Edgard Blü- cher, 2005.

KARAGIANNIS, A.. Soft disability in schools: assisting or confining at risk children na youth? In: Journal of Education Thought, Calgary, v.34, n. 2, p. 113 - 134, 2000.

LAUFER, Adriana Mariana; PAZMINO, Ana Verônica. Parâmetros de projeto para equipamento lúdico em espaços públicos baseados nos princípios do design universal. In: Cadernos da Escola de Comunicação. v. 1, n. 4 , 2006. Disponível: http://revistas.unibrasil.com.br/cadernoscomunicacao/index.php/comunicacao/article/view/42

. Acesso: 06 de maio de 2017.

LOCH, MÁRCIA DO VALLE PEREIRA. Convergência entre Acessibilidade Espacial Escolar, Pedagogia Construtivista e Escola Inclusiva. Doutor em Engenharia de Produção, no Programa de Pós-graduação em Engenharia de Produção da Universidade Federal de Santa Catarina. Florianópolis, 21 de junho de 2007.

LUCIO, Cristina do Carmo. Análise da acessibilidade e usabilidade de equipamentos médico-hospitalares para pacientes obesos da cidade de Bauru (SP). Dissertação (Mestrado) - Universidade Estadual Paulista. Faculdade de Arquitetura, Artes e Comunicação, Bauru, 2007. 110p..

MANTOAN, Maria Teresa Eglér (org). 0 desafio das diferenças nas escolas. Petrópolis, RJ: Vozes, 2008.

MORAES, Anamaria de; MONT'ALVÃO, Cláudia. Ergonomia: conceitos e aplicações. $4^{\circ}$ Edição. Rio de Janeiro: 2AB Editora, 2010. 232p..

MULLER, Marcelle Suzete; ALMEIDA, Eloisa Santa de; TEIXEIRA, Fábio Gonçalves. Design inclusivo: Playground para Todas as Crianças. In: Human Factors in Design, v.3, $\begin{array}{llllll}\text { n.5, } & \mathrm{p} & 02 & - & 27, & 2014 .\end{array}$ www.revistas.udesc.br/index.php/hfd/article/download/5072/4127. Acesso: 25 de abr. de 2017.

ORNSTEIN, S.. Desempenho do Ambiente Construído, Interdisciplinaridade e Arquitetura. São Paulo: FAUUSP, 1996.

ORNSTEIN, SHEILA WALBE. POSTOCCUPANCY EVALUATION PERFORMED IN ELEMENTARY AND HIGH SCHOOLS OF GREATER SÃO PAULO, BRAZIL: THE OCCUPANTS AND THE QUALITY OF THE SCHOOL ENVIRONMENT. IN: ENVIRONMENT AND BEHAVIOR, 1, 1997. DISPONÍVEL: HTTP://JOURNALS.SAGEPUB.COM/DOI/ABS/10.1177/001391659702900205?JOURNALC ODE=EABA. ACESSO: 28 DE ABR DE 2017.

ORSNTEIN, S; BRUNA, G.; ROMÉRO, M. Ambiente construído e comportamento: a avaliação pós-ocupação e a qualidade ambiental. São Paulo: Ed. Nobel - FAUUSP, 1995. 


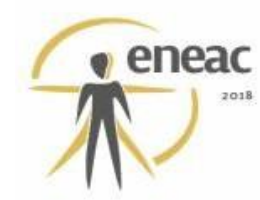

PIVIK, Jayne Renee. The perspective of children and youth: How different stakeholders identify architectural barriers for inclusion in schools. In: Journal of Environmental Psychology, Volume 30, Issue 4, December 2010, Pages 510-517. Disponível: http://www.sciencedirect.com/science/article/pii/S0272494410000253. Acesso: 28 de abr de 2017.

RABINOWITZ, Harvey Z. Postoccupancy Evaluation. Introduction to Architecture. McGraw-Hill, 1979.

REFSHAUGE, Anne Dahl; STIGSDOTTER, Ulrika K.; LAMM, Bettina; THORLEIFSDOTTIR, Kristin. Evidence-Based Playground Design: Lessons Learned from Theory to Practice. In: Journal Landscape Research, vol 40, 2013. Pag. 226 - 246. Disponível: http://www.tandfonline.com/doi/full/10.1080/01426397.2013.824073?scroll=top\&needAccess =true. Acesso 29 de abr de 2017.

RHEINGANTZ, Paulo Afonso; AZEVEDO, Giselle Arteiro; BRASILEIRO, Alice; QUEIROZ, Mônica. Observando a qualidade do lugar: procedimentos para a Avaliação PósOcupação. Rio de Janeiro: Universidade Federal do Rio de Janeiro, Faculdade de Arquitetura e Urbanismo, Pós-Graduação em Arquitetura, 2009. 117 p .. Disponível em: http://www.fau.ufrj.br/prolugar/assets/obs_a_qua_lugar.pdf. Acesso em 25 abr. 2017.

VIGOTSKI, L. S.. A formação social da mente. São Paulo: Martins Fontes. 1998.

UNITED STATES ACCESS BOARD. Accessible Play Areas: a summary of accessibility guidelines for play areas. 2005. Acesso em: 17 dez. 2008.

WATSON, Chris Watson; THOMSON, Keith. Bringing Post-Occupancy Evaluation to Schools in Scotland. In: Evaluating Quality in Educational Facilities, 2005.

ZHANG, Yufan; BARRET, Peter. Findings from a post-occupancy evaluation in the UK primary schools sector. In: Facilities, Vol. 28, 2010. Issue: 13/14, pp.641-656, doi: $10.1108 / 02632771011083685$.

Disponível: http://www.emeraldinsight.com/doi/abs/10.1108/02632771011083685. Acesso: 28 de abr de 2017. 